\title{
The "harlequin" sign and congenital Horner's syndrome
}

\author{
D A Morrison, K Bibby, G Woodruff
}

\begin{abstract}
When trying to establish the likely anatomical site (preganglionic or postganglionic) of a lesion causing congenital Horner's syndrome, the distribution of facial flushing (the "harlequin" sign), may be seen. In babies and young children, facial flushing is a relatively simple clinical sign to demonstrate, compared with facial sweating. In unilateral facial flushing the areas that do not flush are almost always identical to the anhidrotic areas. However, neither facial flushing nor testing the pupil reactions with pholedrine or hydroxyamphetamine can be relied on to predict the probable site of any lesion causing congenital Horner's syndrome. Two patients with congenital Horner's syndrome are presented which demonstrated the "harlequin" sign and in whom clinical examination and pharmacological testing gave conflicting evidence for localisation of the site of the causative lesion. The presentation of congenital Horner's syndrome should be investigated and include MRI or CT to exclude a serious underlying cause.
\end{abstract}

\section{(F Neurol Neurosurg Psychiatry 1997;62:626-628)}

Keywords: congenital Horner's syndrome; pholedrine

The clinical features of congenital Horner's syndrome include upper and lower lid ptosis, pupil miosis, iris hypochromia, and anhidrosis of the face and upper limbs on the affected side.

Classically, the cause of congenital Horner's syndrome has been birth trauma resulting in brachial plexus injury (Klumpke's palsy). More sinister aetiologies, such as neuroblastoma and carotid artery thrombosis, are occasionally seen..$^{1-3}$ However, in many cases no cause is found, despite extensive investigation. ${ }^{3}$

The diagnosis of Horner's syndrome is confirmed pharmacologically by the use of $4 \%$ cocaine drops, which cause an increase in anisocoria (difference in pupil size). ${ }^{4}$ Clinically, localisation of the probable site of the lesion (presuperior or postsuperior cervical ganglion) may be made by observing the distribution of anhidrosis and facial flushing. ${ }^{56}$ The site of the lesion may be determined pharmacologically by testing the response of the pupil to pholedrine drops. ${ }^{7}$ Pholedrine is chemically similar to hydroxyamphetamine, and works by releasing catecholamines from intact nerve endings.

It has been suggested that pharmacological methods of localising sympathetic lesions may be less reliable in congenital Horner's syndrome than acquired Horner's syndrome. ${ }^{5}$ Such atypical responses are not widely acknowledged and may have implications in the management of congenital Horner's syndrome.

We describe two patients with congenital Horner's syndrome in whom clinical examination and pharmacological testing gave conflicting evidence for localisation of the causative lesion.

\section{Case reports}

CASE 1

A 4 month old boy was referred to the eye clinic after his mother noticed that the left eye "looked smaller" than the right. He had been delivered quickly with the cord around his neck but his birth was otherwise normal. Ocular examination showed anisocoria: the right pupil measured $4 \mathrm{~mm}$ in diameter and the left $2 \mathrm{~mm}$. There was narrowing of the left palpebral fissure and left ptosis (fig 1A), but no iris hypochromia. On attempting to instil diagnostic eye drops the child became distressed and flushed all over with the exception of the left side of the face (fig 1B) (facial sweating was not measured). The absence of flushing suggested a left preganglionic Horner's syndrome. The diagnosis of left Horner's syndrome was confirmed with $4 \%$ cocaine drops.

General examination was normal with no limb weakness. Pholedrine drops were instilled into both eyes and after 40 minutes the right pupil measured $7 \mathrm{~mm}$ and the left $4 \mathrm{~mm}$, this increase in anisocoria being typical in a postganglionic Horner's syndrome. Magnetic resonance imaging of the head, neck and thorax was normal. One year later this boy was well, but still showed asymmetric facial flushing when distressed or in hot weather. 
Figure 1 (A) Case 1: left congenital Horner's syndrome. (B) Case 1: left congenital Horner's syndrome showing asymmetric facial flushing.

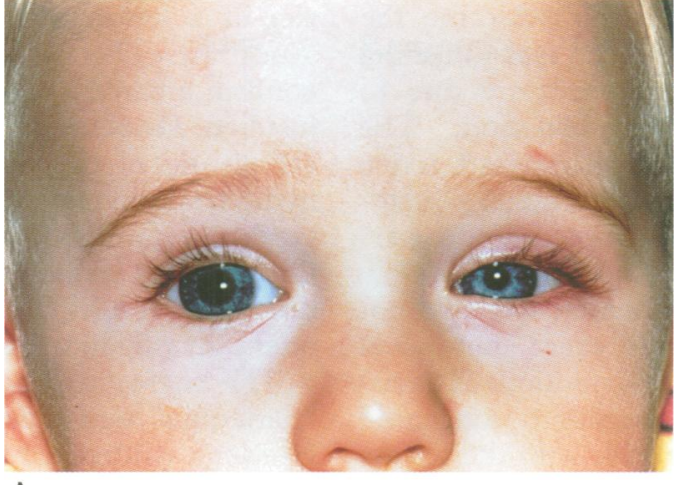

A

CASE 2

A 7 year old boy presented to the eye clinic with the right pupil smaller than the left since birth. His mother stated that after exercise, in hot weather, or when upset, the left side of his face and upper chest would go red whereas the right side of his face did not. Examination showed the right pupil to be $3 \mathrm{~mm}$ in diameter and the left $5 \mathrm{~mm}$, and there was $1.5 \mathrm{~mm}$ of right ptosis. There was no iris hypochromia. Visual acuity was $6 / 6$ right and left. The right pupil did not change in size after the addition of $4 \%$ cocaine drops whereas the left dilated to $8 \mathrm{~mm}$, confirming the diagnosis of a right Horner's syndrome. After running indoors and climbing stairs for a few minutes, there was a pronounced asymmetric flushing of the face with the left side red and sweaty compared with the right, implying a preganglionic lesion on the right side (fig 2). Some weeks later, pupil testing with pholedrine drops caused the left pupil to increase in size from 5 $\mathrm{mm}$ to $6 \mathrm{~mm}$. The right pupil remained at 3 $\mathrm{mm}$, suggesting a postganglionic lesion.

General examination was normal and MRI

Figure 2 Case 2: right congenital Horner's syndrome with asymmetric facial flushing (after 4\% cocaine drops).

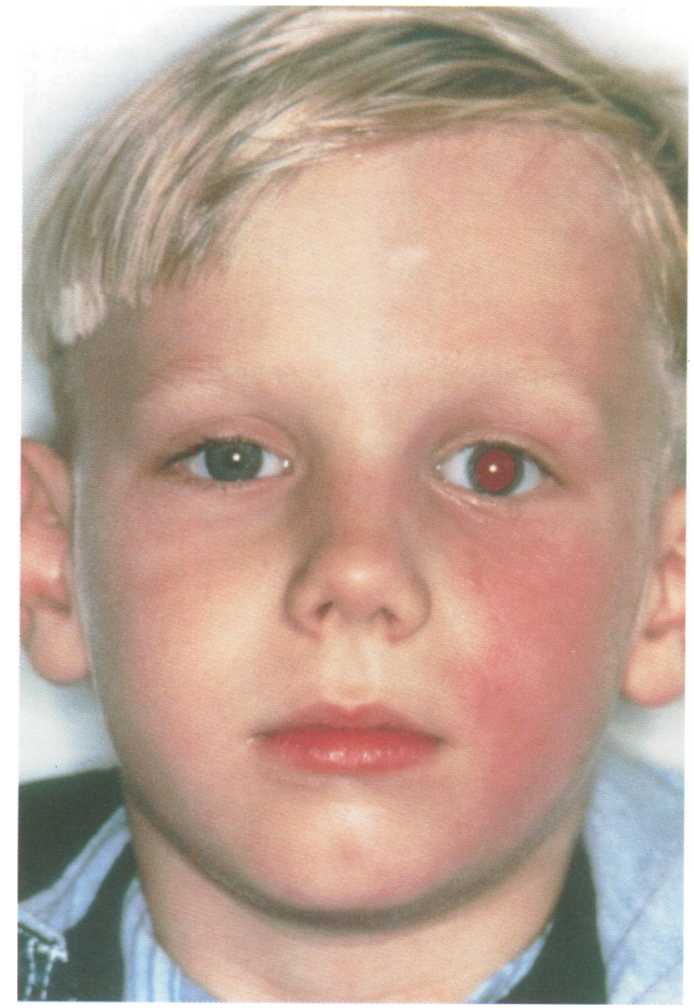

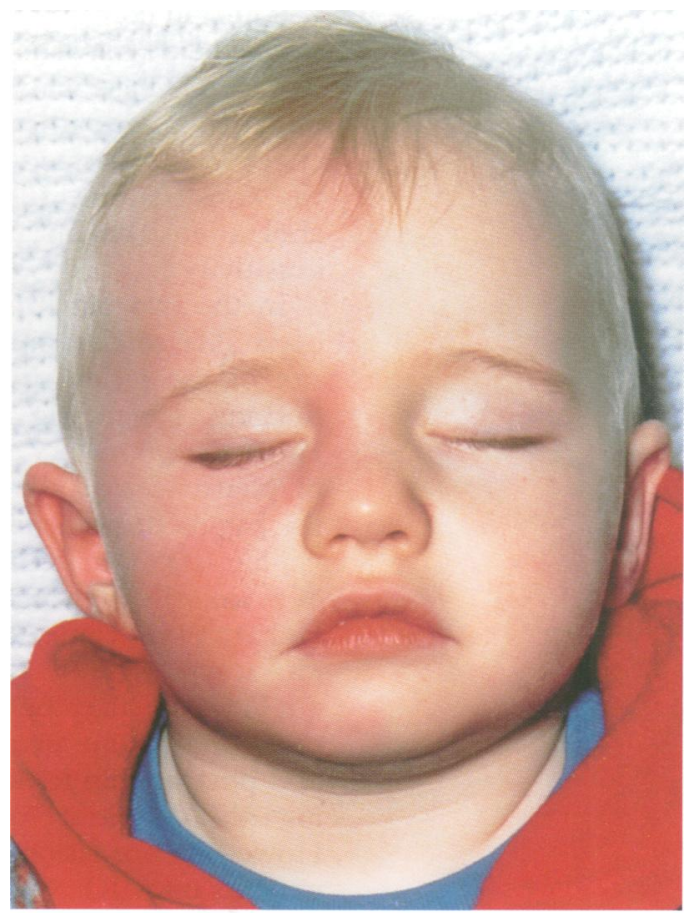

$\mathrm{B}$

of the brain, neck, and thorax did not show any paravertebal mass or abnormal signal.

\section{Discussion}

Congenital Horner's syndrome may be recognised clinically by the features of blepharoptosis, miosis, facial anhidrosis, and iris hypochromia. The diagnosis can be confirmed with cocaine drops. ${ }^{4}$

Hydroxyamphetamine drops (1\%) are highly effective in distinguishing preganglionic and postganglionic lesions. ${ }^{8}$ With a postganglionic lesion the pupil fails to dilate; with a preganglionic lesion the affected pupil dilates the same as or more than the normal side. Hydroxyamphetamine drops are no longer available in the United Kingdom, but pholedrine (Ankerpharm $\mathrm{GmBH}$, Ankerwerk Rudolstadt, Germany) is structurally similar to hydroxyamphetamine and has been shown to be comparable in its effects. ${ }^{7}$

The distribution of sweating in Horner's syndrome is valuable in localising the site of the lesion clinically. ${ }^{6}$ The anatomical pathways concerned with thermoregulatory facial sweating are well established. ${ }^{9}$ When the lesion is proximal to the bifurcation of the common carotid artery there is hemifacial anhidrosis on the affected side, and when the lesion is distal the loss of sweating is confined to the medial aspect of the forehead. In patients not showing anhidrosis or with only mild asymmetry there is no localisation value, and many of these will have central lesions.

In unilateral facial flushing the areas that do not flush are virtually identical to the anhidrotic areas. ${ }^{5910}$ Both thermoregulatory facial flushing and emotional vasodilatation are thought to be mediated by the cervical sympathetic pathways, ${ }^{9}$ travelling for the most part with branches of the external carotid artery. 
Thus, in congenital Horner's syndrome, the affected side may show reduced facial flushing and a decrease in skin temperature due to impaired sympathetic vasodilatation. The effect is exaggerated by superimposed active vasoconstriction due to circulating catecholamines (enhanced by denervation hypersensitivity ${ }^{5}$ ).

In the two patients presented we have not been able to determine the exact anatomical site of the lesion. The distribution of facial flushing, suggesting preganglionic congenital Horner's syndrome, is at odds with the results of pharmacological testing. The response of the pupils to pholedrine, implying a postganglionic lesion, and the simultaneous presence of a clinically preganglionic lesion in congenital Horner's syndrome, could be explained in various ways.

(1) There may be a diffuse lesion or more than one lesion involving the preganglionic and postganglionic neuron, or a lesion affecting the superior cervical ganglion itself. ${ }^{5}$ However, no lesion was detectable in our patients on MRI.

(2) The pharmacological evidence may be incorrect, or the pupil response to pholedrine in congenital Horner's syndrome may be different from hydroxyamphetamine, although there is no evidence to suggest this. ${ }^{7}$ Hydroxyamphetamine mydriasis is highly effective in distinguishing preganglionic from postganglionic lesions. Maloney et $a l^{11}$ found that, for a known peripheral (postganglionic) Horner's lesion, $1 \cdot 0 \%$ hydroxyamphetamine drops correctly localised the lesion in 70 out of 72 cases, a diagnostic accuracy of $97 \%$. For more proximal (preganglionic) lesions, the diagnostic accuracy was $84 \%(75 / 89)$.

(3) The evidence for a preganglionic lesion (based on the facial flushing) may be incorrect. However, of over 30 patients with known lesions of the sympathetic pathway described by several authors, ${ }^{5910}$ none provide convincing contradictory evidence.

We favour the theory that an orthograde transynaptic degeneration ${ }^{5}$ across the superior cervical ganglion can occur in Horner's syndrome that is congenital or acquired very early in life, when a preganglionic lesion can give rise to some features typically regarded as postganglionic. Secondary involvement of postganglionic fibres could explain both the result of pharmacological testing and the exaggeration of facial flushing due to denervation hypersensitivity.

Neither facial flushing nor testing with pholedrine should be relied on to predict the site of a lesion causing congenital Horner's syndrome. The use of $4 \%$ cocaine drops to confirm a clinical diagnosis would seem to be justified. However, the value of pharmacological testing of the pupils with pholedrine or hydroxyamphetamine in congenital Horner's syndrome must be questioned, particularly as this may not be easy or practical in small children. The results have no influence on subsequent investigation or management.

The interesting but largely unacknowledged "harlequin" sign in association with congenital Horner's syndrome has been illustrated; asymmetric facial flushing should alert the clinician to the possibility of Horner's syndrome. In a possible case of congenital Horner's syndrome, the "harlequin" sign should be sought. It is easier to show than facial anhydrosis, particularly in small babies, although its value as a localising sign has yet to be defined. Therefore, to what extent and when should the presentation of congenital Horner's syndrome be investigated? As has already been implied, pharmacological study other than cocaine drops is of academic interest only. In the absence of any physical signs to suggest the site of the lesion, the recommended investigation for congenital Horner's syndrome is MRI or CT of the head, neck, and thorax to exclude neuroblastoma and other serious pathology, such as carotid artery thrombosis. If possible, a 24 hour urine assay for catecholamines should be performed to exclude elevated concentrations of vanilylmandelic acid. $^{1-3}$

We thank the parents for their permission to reproduce the figures and Peter Burberry, Senior Pharmacist, The Leicester Royal Infirmary NHS Trust.

1 Sauer C, Levinsohn MW. Horner's syndrome in childhood. Neurology 1976;26:218-20.

2 Musarella MA, Chan HSL, DeBoer G, Gallie BL. Ocular involvement in neuroblastoma: prognostic implications. Ophthalmology 1984;91:936-40.

3 Woodruff GH, Buncic JR, Morin JD. Horner's syndrome in children. Fournal of Paediatric Ophthalmology and Strabismus 1988;25:1:40-4.

4 Kardon RH, Denison CE, Brown CK, Thompson HS Critical evaluation of the cocaine test in the diagnosis of Horner's syndrome. Arch Ophthalmol 1990;108.384-7.

5 Weinstein JM, Zweifel TJ, Thompson HS. Congenital Horner's syndrome. Arch Ophthalmol 1980;98:1074-8.

6 Morris JGL, Lee J, Lim CL. Facial sweating in Horner's syndrome. Brain 1984;107:751-8.

7 Wilhelm $H$. Pupil examination and evaluation of pupillary disorders. Neuro-ophthalmology 1994;14:283-95.

8 Cremer SA, Thompson S, Digre KB, Kardon RH Hydroxyamphetamine mydriasis in Horner's syndrome. Am $\mathcal{F}$ Ophthalmol 1990;110:71-6.

9 Drummond PD, Lance JW. Facial flushing and sweating mediated by the sympathetic nervous system. Brain 1987;110:793-803.

10 Lance JW, Drummond PD, Gandevia S. Harlequin syndrome: the sudden onset of unilateral flushing and sweating. F Neurol Neurosurg Psychiatry 1988;51:635-42.

11 Maloney WF, Young BR, Moyer NJ. Evaluation of the causes and accuracy of pharmacologic localisation in Horner's syndrome. Am F Ophthalmol 1980;90:394-402. 